CCC 2019

Proceedings of the Creative Construction Conference (2019) 119

Edited by: Miroslaw J. Skibniewski \& Miklos Hajdu

https://doi.org/10.3311/CCC2019-119

Creative Construction Conference 2019, CCC 2019, 29 June - 2 July 2019, Budapest, Hungary

\title{
Micro BIM adoption in design firms: Guidelines for doing a BIM implementation plan
}

\author{
Elodie Hochscheid ${ }^{\mathrm{a} *}$, Gilles Halin ${ }^{\mathrm{a}, \mathrm{b}}$ \\ ${ }^{a}$ MAP-CRAI (UMR 3495 CNRS/MC), Ecole Nationale Supérieure d'Architecture de Nancy, 2 rue Bastien Lepage, 54000, Nancy, France \\ ${ }^{b}$ Université de Lorraine, 54000, Nancy, France
}

\begin{abstract}
Building Information Modeling (BIM) adoption is significantly increasing and is highly supported by governmental bodies because it has great potential for the construction sector. Nevertheless, some firms do not know how to proceed for implementation. Many design firms have also already adopted BIM, so feedback is now available: several research on BIM implementation have shown that there is a lack of understanding of implementation process and a need for guidelines. Moreover, these research work, case studies and action-research have not been cross-referenced in any significant way to deduce generic and adapted guidelines for firms that are now embracing BIM implementation. In this paper, guidelines for doing a four-phases BIM implementation plan are proposed, by referencing, cross-checking, comparing, and synthetizing case studies of BIM implementation in design firms and change management literature.
\end{abstract}

(C) 2019 The Authors. Published by Budapest University of Technology and Economics \& Diamond Congress Ltd.

Peer-review under responsibility of the scientific committee of the Creative Construction Conference 2019.

Keywords: BIM; BIM implementation;micro adoption; design firms; guidelines; implementation plan; change management

\section{Introduction}

Building Information Modeling (BIM) adoption is increasing and is highly supported by governmental bodies because it has great potential for the construction sector. But BIM is not only a technical move, it's difficult to implement and disrupts firms' habits and practices: it is a significant organizational change. Many firms have already adopted BIM, others are much more reluctant. There are also firms who would like to implement BIM but do not have the economic opportunity to do so or do not know how to proceed [1]. Factors affecting adoption of a technology change over time as the adoption life cycle proceeds [2] : those who implement later will be more sensitive to implementation risks and more skeptical [3], it affects the implementation process [4].

Firms that implement BIM today may thus not have the same profile and motivations as those who have already done so. According to very recent surveys [5], French architects who are implementing BIM now are in "early majority" or "late majority" adopters' category. These adopters can however benefit from innovators and early adopters experience.

The purpose of this research work is to propose reliable and generic indications (guidelines) for firms that wish to implement BIM. These guidelines are based on previous case studies found in BIM-specific and change management

*Corresponding author: Author email: elodie.h@crai.archi.fr 
Elodie Hochscheid and Gilles Halin / Proceedings of the Creative Construction Conference (2019) 119 https://doi.org/10.3311/CCC2019-119

literature. In a first part, outlines of research are drawn. In a second part, BIM implementation case studies are reviewed and compared to extract similarities. In a last part, guidelines for doing a four-phase implementation plan is proposed, in line with the aforementioned elements.

\section{Research outlines}

In this section, outlines of the research are drawn and research is positioned in relation to others in literature on three dimensions: (1) the organizational scale, (2) the adoption process stages, (3) the type of BIM knowledge content.

\subsection{Organizational scale of the research: micro level}

BIM is now a competitive leverage of construction sectors all around the world. For this reason, many studies and reports have compared different counties in their BIM adoption maturity and policies [6-9]. These studies focus on the macro level. It is also possible to provide guidelines to a project team for BIM implementation (meso level), or to a firm (micro level). These three levels have clear definitions in the context of BIM; each one has a different policy maker to whom guidelines for adoption can be addressed to (Tab. 1.).

Table 1. Granular organizational scale according to [10], and related policy makers.

\begin{tabular}{lll}
\hline Level & Definition of the level & Policy-maker \\
\hline MACRO & Markets and industries & Governments, international institutions \\
MESO & Projects and their teams & Owner, project manager \\
MICRO & Organization (firm) & Top management of a firm \\
\hline
\end{tabular}

Regardless of project teams, integrating BIM in a firm is a radical organizational change. The micro level must therefore also be subject to guidelines for implementation but has been little studied so far. Micro-level centered studies point out that:

- There is a lack of clarity in the adoption process and it is needed to provide specific support services (guidelines, frameworks) for firms who implement BIM [11-14], specifically to SMEs [12,15].

- Firm who implement need to manage change [16,17], and review their business process strategy [15]

- There is a need of studying factors that affect implementation to be able to provide adequate guidelines $[12,16,18]$

This paper is micro-level centered, as it aims to provide tools for firms to manage BIM implementation.

\subsection{Adoption stages covered by the research: implementation and confirmation}

The adoption process is composed of 5 stages (Fig. 1.). Implementation (a set of activities undertaken to deploy BIM in the firm to improve specific deliverables and workflows) is only one stage of the adoption process, and is followed by the confirmation stage (when the firm evaluates if new processes are adapted and if they can keep and improve them or have to abandon them). This research covers implementation and confirmation stages of the adoption process.

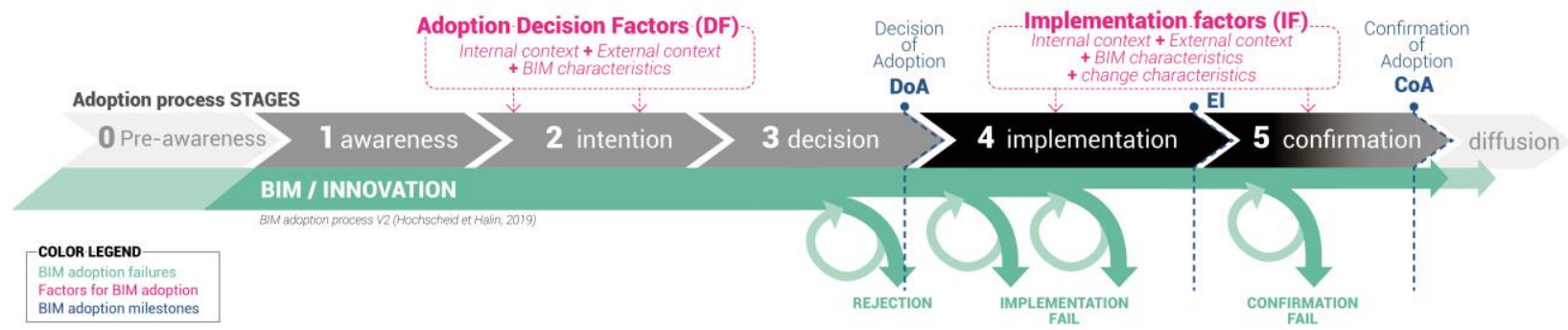

Fig.1. adoption process ( [19], adapted from [3,20]) 
Elodie Hochscheid and Gilles Halin / Proceedings of the Creative Construction Conference (2019) 119 https://doi.org/10.3311/CCC2019-119

It is needed to know what makes implementation/confirmation fail or succeed (implementation factors (Fig. 1.)) to build recommendations for firms to implement BIM $[12,16,18]$. Indeed, the way in which the change is implemented impacts the success of the implementation [22], hence the interest of proposing guidelines to firms. In general terms, factors that affect organizational change are: internal context, external context, characteristics of innovation, and change characteristics [19] (Fig. 1.). Yet, factors affecting implementation are rarely included on researches studying factors that affect the BIM adoption process. Very recently, a BIM adoption taxonomy which studies the impact of factors throughout the adoption process has been proposed [21] but only includes stages before DoA (Fig. 1.).

\subsection{Type of BIM knowledge content proposed: guidelines for designing an implementation plan.}

There are many types of documents and content whose purpose is to facilitate BIM diffusion and adoption: roadmaps, guidelines, frameworks, plans, procedures, protocols, best practice, and so on. In the BIM Knowledge Content Taxonomy (KCT) [23], these content are classified in three different categories: 1- Guides (descriptive and optional), 2- Protocols (prescriptive and optional), 3-Mandates (prescriptive and mandatory).

Change in an organization is not easy to form exactly as intended and change management strategies are numerous [24]. The proposed solution must therefore not be formal too much and allow firms to integrate their own context and strategy. The proposal will consequently take the form of guidelines* for helping top-management of firms to make their own implementation plan*. Guidelines for implementing BIM is different from guidelines for using it. This is similar to the distinction between installing software and using it.

- Guidelines are "a compilation of several BIM content types with the aim of providing guidance to individuals, teams or organizations" [23] (descriptive document, guide in the KCT)

- A plan is "a document describing activities to be performed, resources to be used and milestones to be reached within a defined timeframe" [23] (prescriptive document, protocol in the KCT)

\section{Guidelines for BIM implementation plan: an overview}

In this section, research that focused on guidelines and implementation plan for micro-level in design firms are crossreferenced to identify the main themes addressed during BIM implementation. Most of them are related to actionresearch and case studies. It should be mentioned that it has been difficult to collect them because of a nonhomogeneous use of vocabulary in literature (implementation is used in lieu of adoption and vice-versa, and almost identical content proposals are given different names, see Appendix A). It causes Systematic Literature Review to become inoperative here. Papers have been selected throughout our work, and all concern practical BIM implementation in design firms and the organizational change that this implies. In the following sections, research have been cross-referenced on (1) aspects of change addressed, and (2) the different views and concepts raised in each study.

\subsection{Overview of the aspects of change addressed}

The aspects of change related to implementation addressed in literature have been listed and classified in Fig.2. into three different categories inherited from [19] :

- Dimension of change ("Dim."): extent over time, within the company and the amount of change to be achieved.

- Involvement of people in change (“Inv.”): motivation, and people's attitude towards change

- Deployed solutions: solutions, tools, deliverables and methods deployed to implement BIM.

Fig.2. shows that any change aspect is very largely covered, and no study cover all aspects. It supports the need of an overview and reliable guidelines for BIM implementation. Maybe the studies address only a few aspects at time because a few companies were included for each experimentation: deployed solutions were adapted to firms' needs and not all solutions are relevant in all cases. 
Elodie Hochscheid and Gilles Halin / Proceedings of the Creative Construction Conference (2019) 119 https://doi.org/10.3311/CCC2019-119

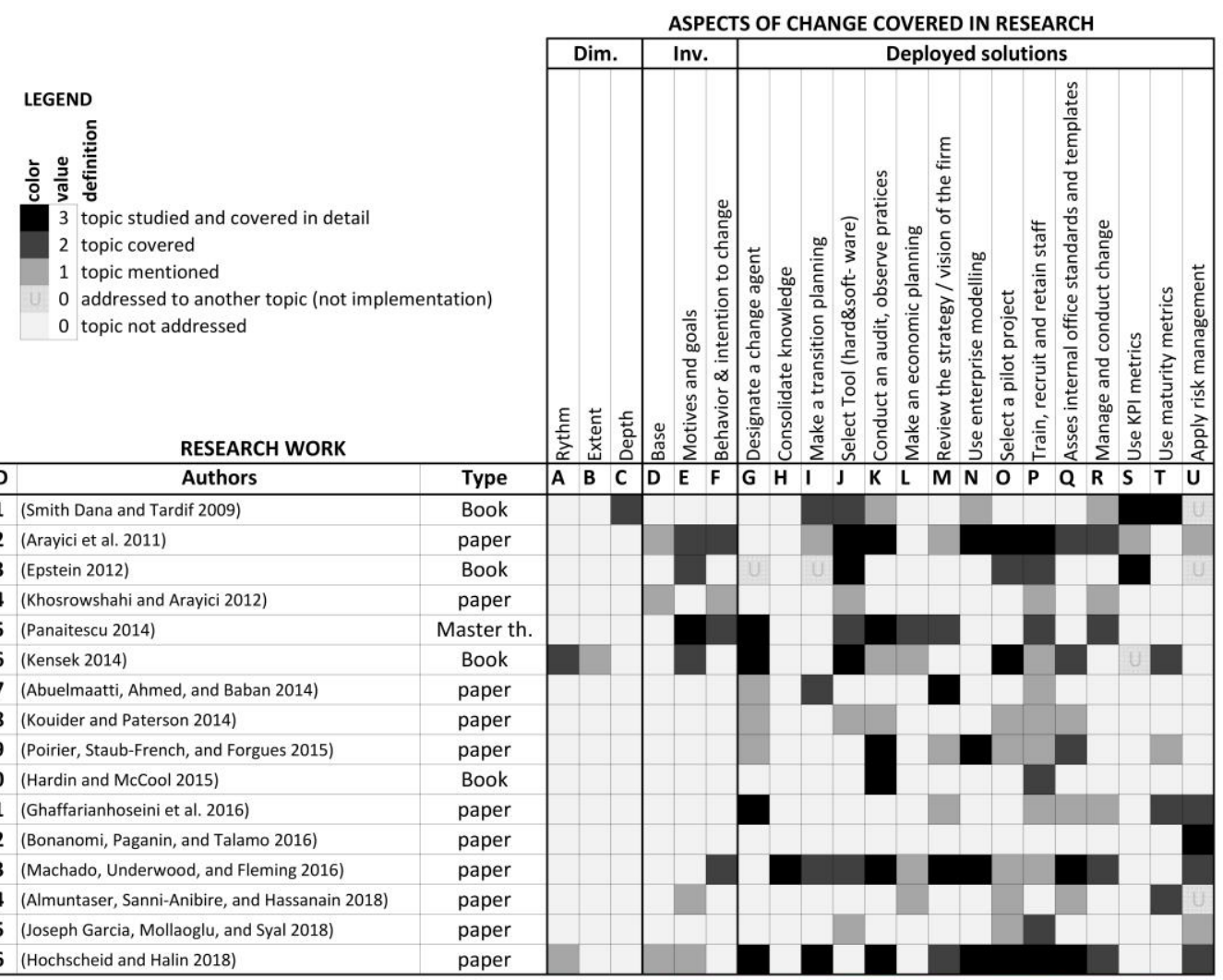

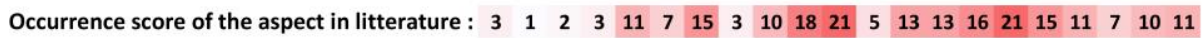

Fig.2. Cross-checking table of the aspects of change (columns) integrated in different studies (lines). See appendix A to link ID with reference. Reading note: the more an aspect is discussed in detail in a research, the darker the associated cell will be (see legend). The higher the occurrence score (OS), the more the aspect has been addressed in the literature. The OS of an aspect is calculated by adding scores of all cells in columns.

Reading the table on the columns reveals aspects that are the most covered. According to occurrence scores (Fig. 2.), aspects $\mathrm{K}, \mathrm{P}$ and $\mathrm{J}$ are highly discussed, whereas aspects $\mathrm{B}, \mathrm{C}, \mathrm{A}, \mathrm{D}$ and $\mathrm{H}$, are very little covered. In general terms, deployed solutions are more covered than dimension of change and people involvement. These two categories are indeed more conceptual, but their absence of the literature may be an indicator that we currently lack a theoretical framework to grasp implementation. Another noteworthy element is that some aspects are misapplied: risk management (U, Fig. 2.) is often applied for BIM project but it is different to apply a risk-response strategy for preventing implementation failure [25]. This table can also be used to cross-reference rows and columns, to identify the reference that can give information on a particular aspect for Tab. 2.

\subsection{Different views of implementation.}

The selected papers show different angles of implementation and reveal various concepts of it. In this section, implementation strategies are compared to each other to extract the concepts inherent of implementation.

Fig. 3. shows phases (in grey) of the execution plan with deliverables for each of them (text at orange arrow tips). The main phases are: observing, planning, taking action, and anchoring change. It also shows the iterative process adopted for the research (blue arrows) in each phase as a validation process. In [1], this iterative process has not only been recommended for research methodology, but to run the implementation plan as a validation process. These implementation plans (Fig. 3, App B., App. C, [1]) present very similar phases, with a diagnosis, a plan, a monitoring step, and an anchoring/dissemination phases. The proposed phases can be found and have been formalized in nonBIM-specific change management literature. It is, for example, commonly admitted that "diagnosis is the basis for action in any managed change effort" [26]. 


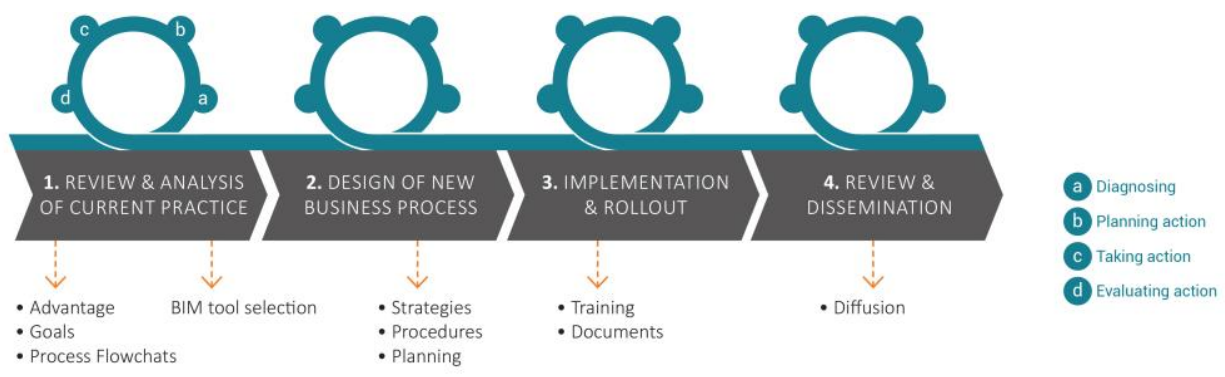

Fig. 3. Implementation plan and action-research method, adapted from [14,17]

Fig. 4. represents effectiveness during implementation phases and across time. It is a bit misleading because it doesn't reflect the loss of effectiveness that firms experience during implementation (the learning process reduces productivity), but it expresses stabilization and progression phases (intra-firm diffusion [27] in the other models).

Fig. 5. represents relations between different contexts during implementation: it addresses micro (management, BIM committee and employees), meso (project team) and macro (external context) levels. It illustrates a continuous improvement firms are experimenting at each new project. It refers to operational learning [28] and has to be linked with other levels of learning to become organizational learning.
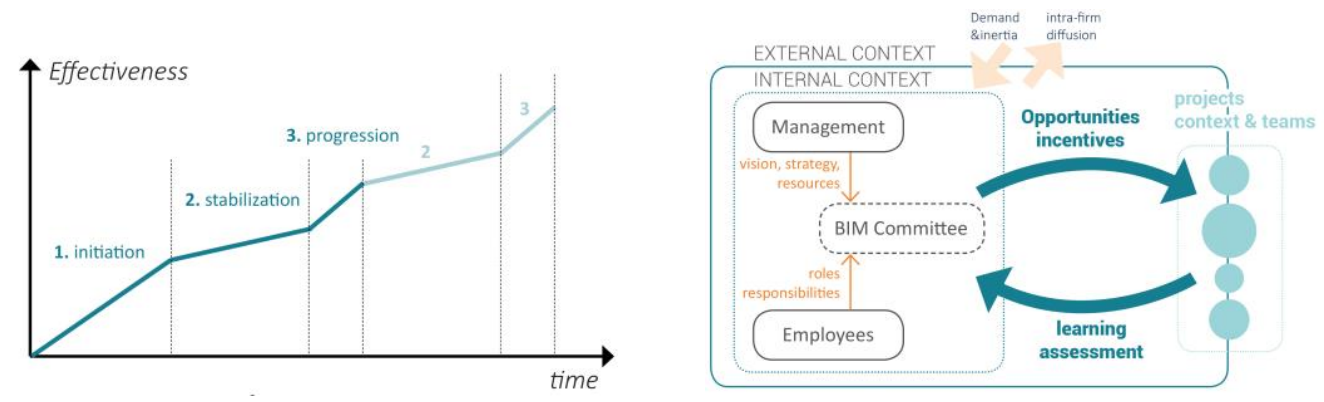

Fig. 4. (left) : Phases and effectiveness of BIM implementation [29],

Fig. 5. (right) : Embedded contexts of BIM adoption and implementation, adapted from [12].

Fig. 6. Dissects the different components of an organization (micro-level) to identify their interactions during implementation. According to this research, there are different path for a conventional and a collaborative technology (like BIM). BIM implementation should then begin at operational level according to [30] and gradually rise upwards strategical level. It may be more a question of going back and forth between these two levels for implementation. The notion of operational learning and strategic vision is therefore also present here.

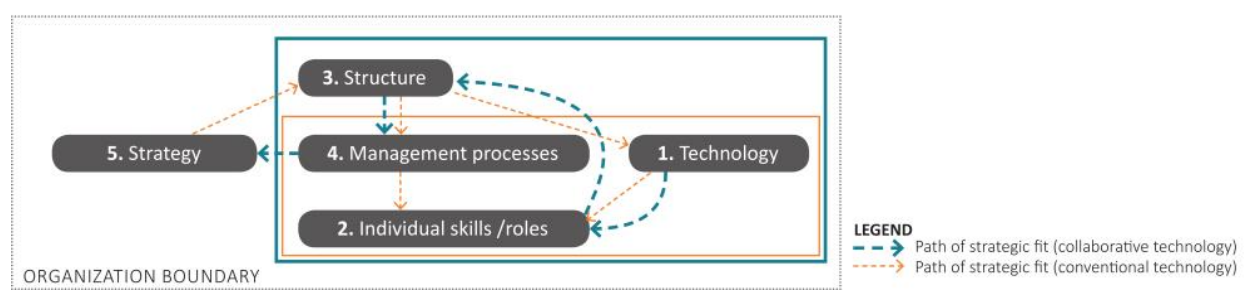

Fig. 6. Path of strategic fit during implementation of conventional and collaborative technology, adapted from [18,30].

All methods are similar in process and underline complementary concepts. The importance of analysis in organizing change is underlined and confirmed by the literature on change management. Emphasis is also placed on the importance of operational learning and continuous improvement that takes place towards the end of the process. Throughout their lives, companies alternate convergent periods (incremental change activities) and radical or discontinuous change [31,32]; the presence of both change mode is here noticeable without being really made explicit. 


\section{Synthesis and proposal of BIM implementation guidelines for constructing an implementation plan}

Guidelines for helping firms to construct their own implementation plan are here drawn, on the basis of methods compared in section 3.2 and aspects of change studied in section 3.1. It covers the implementation stage, and the beginning of the confirmation stage of the adoption process (Fig. 7.). Transition is organized into four phases, regardless of the level of BIM to be achieved, and of the context of the firm. After an initial period of disruptive change (implementation stage (diagnosis, planning and execution phases), Fig. 7.), new uses are gradually improved and the firm switches from disruptive to progressive change (confirmation stage, anchoring phases) as seen in sect. 3.2.

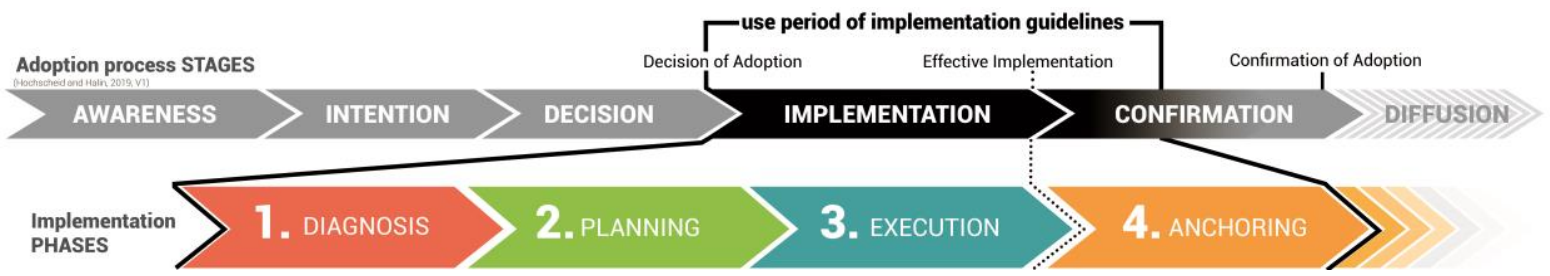

Fig. 7. The four-phases guidelines positioned on the adoption process

Each phase is detailed in two steps (Tab. 2., Fig. 8.). They are defined and connected to detailed solutions' ID (DS ID) seen above (Fig. 2.). These solutions have to be adapted to the context of firms and maturity level to achieve.

Table 2. Guidelines for implementation in design firms

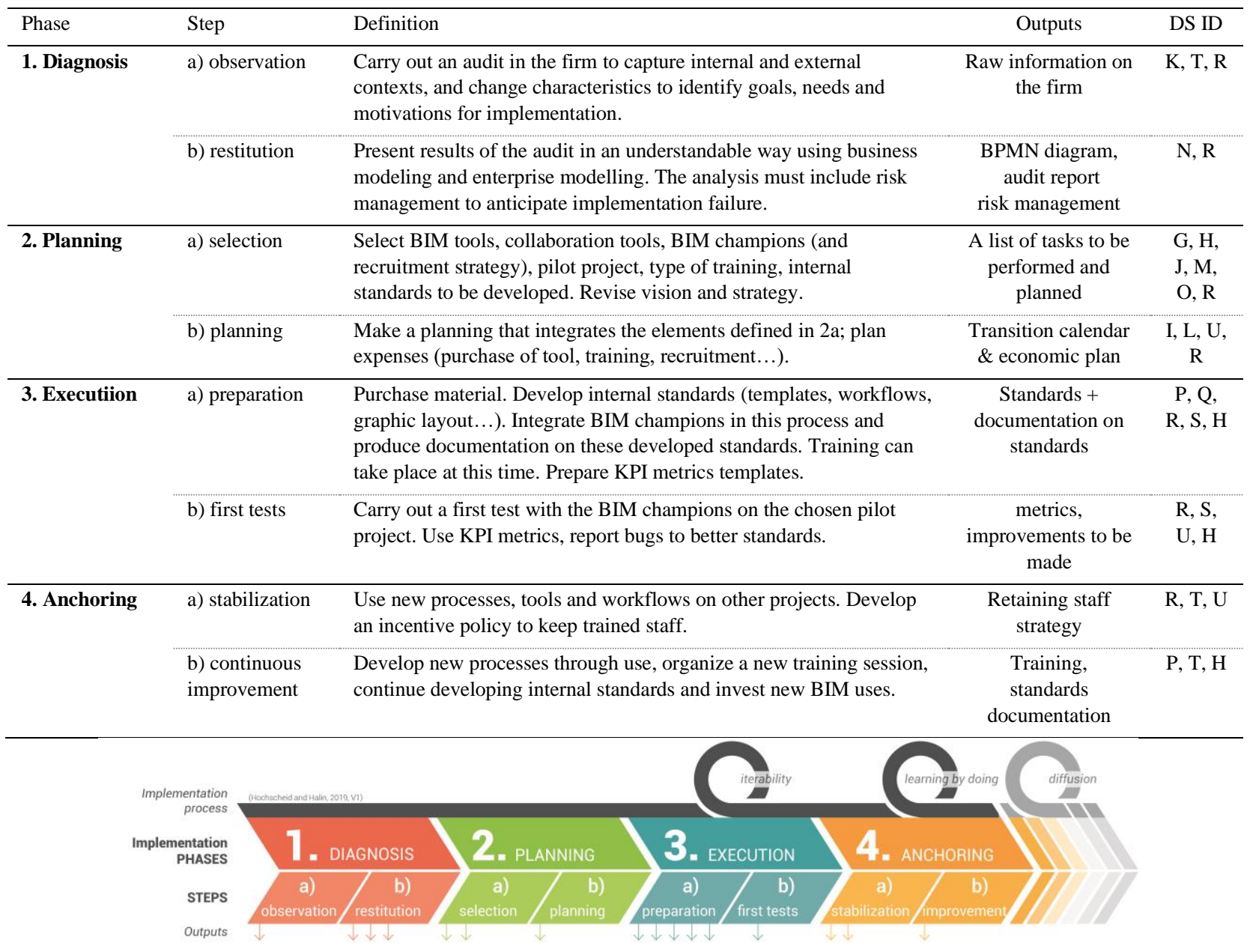

Fig. 8. Detailed process of the proposed guidelines 
Elodie Hochscheid and Gilles Halin / Proceedings of the Creative Construction Conference (2019) 119 https://doi.org/10.3311/CCC2019-119

\section{Conclusion}

Studies that focus on BIM implementation in design firms are rare and often centered on a single case study. They generally underline the lack of clarity in the adoption process, the need for providing specific support services to firms who implement BIM and a need of studying factors that affect implementation to be able to provide these adequate tools. However, these case studies have many similarities in the way the transition is conducted, also common to change management literature. The contribution of this paper are generic guidelines extracted from the comparison of these transition approaches. But these guidelines are not sufficiently developed to be usable by firms: it is necessary to complete the comprehension we have on factors that affect implementation, to propose an adaptation of these guidelines for different firms' internal and external contexts.

\section{Appendix A. Table 3. Various names given for BIM execution plans and guidelines.}

\begin{tabular}{llc}
\hline ID & Name & Ref \\
\hline $\mathbf{0 1}$ & Business Process reform & {$[33]$} \\
$\mathbf{0 2}$ & Iterative action research stages and process & {$[14,17]$} \\
$\mathbf{0 3}$ & Implementing successful Building Information Modeling & {$[34]$} \\
$\mathbf{0 4}$ & Roadmap for implementation & {$[13]$} \\
$\mathbf{0 5}$ & Structured implementation process, BIM implementation plan framework & {$[35]$} \\
$\mathbf{0 6}$ & Steps towards implementation & {$[36]$} \\
$\mathbf{0 7}$ & Path of strategic fit & {$[18]$} \\
$\mathbf{0 8}$ & Migration phases & {$[37]$} \\
$\mathbf{0 9}$ & Embedded contexts of BIM adoption / implementation contexts & {$[12]$} \\
$\mathbf{1 0}$ & Managing change / training BIM personnel & {$[38]$} \\
$\mathbf{1 1}$ & BIM implementation strategy & {$[15]$} \\
$\mathbf{1 2}$ & Implementation framework & {$[25]$} \\
$\mathbf{1 3}$ & BIM implementation approach & {$[16]$} \\
$\mathbf{1 4}$ & Framework for BIM implementation & {$[11]$} \\
$\mathbf{1 5}$ & Phases of BIM implementation & {$[29]$} \\
$\mathbf{1 6}$ & Implementation method & {$[1]$} \\
\hline
\end{tabular}

\section{Appendix B. Implementation plan, adapted from [11]}

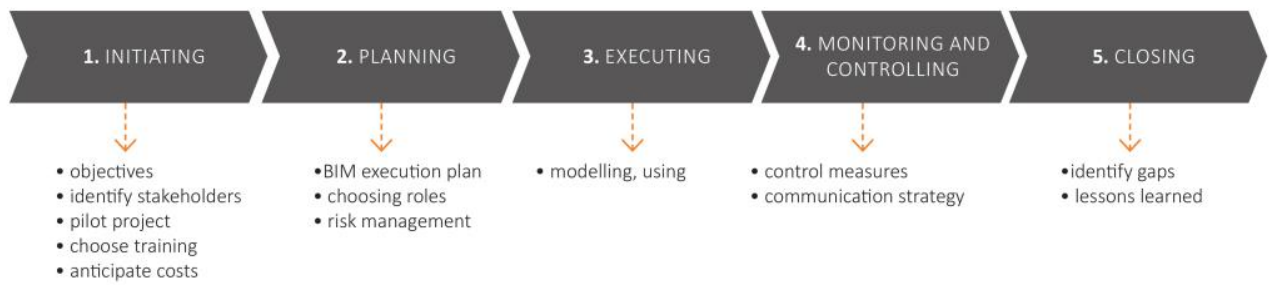

\section{Appendix C. Implementation plan, adapted from [16]}

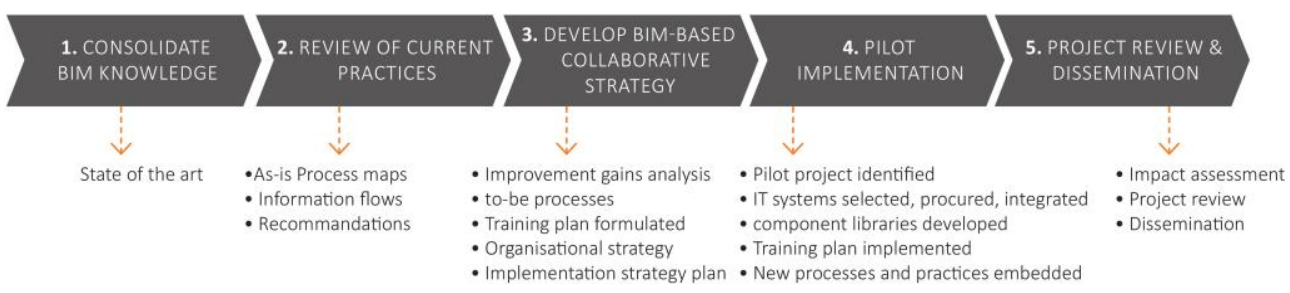




\section{References}

[1] E. Hochscheid, G. Halin, BIM implementation in architecture firms : Interviews,case studies and action research used to build a method that facilitates implementation of BIM processes and tools, in: Proceedings of the 36th ECAADe Annual Conference, Lodz, Poland, 2018 : p. 10.

[2] E. Waarts, Y.M. van Everdingen, J. van Hillegersberg, The dynamics of factors affecting the adoption of innovations, Journal of Product Innovation Management. 19 (2002) 412-423. doi:10.1016/S0737-6782(02)00175-3.

[3] E.M. Rogers, Diffusion of Innovations, 5th Edition, Simon and Schuster, 2003.

[4] J.L. Franklin, Characteristics of successful and unsuccessful organization development, The Journal of Applied Behavioral Science. 12 (1976) 471-492. https://doi.org/10.1177\%2F002188637601200402

[5] Groupe BATIACTU, Le BIM dans le secteur du BTP, résultats de la 3e enquête réalisée pour le baromètre du PTNB sur l'utilisation des outils numériques et digitaux par les professionnels du bâtiment, (2018). https://bit.ly/2X7tgXD.

[6] McGraw Hill Construction, The Business Value of BIM for Construction in Major Global Markets: How contractors around the world are driving innovations with Building Information Modelling, Smart MarketReport. (2014).

[7] NBS, A. Malleson, H. Kato, B. Popíšilová, D. Watson, G. Friborg, NBS International BIM Report 2016, (2016).

[8] M. Kassem, B. Succar, Macro BIM adoption: Comparative market analysis, Automation in Construction. (2017).

[9] B. Succar, M. Kassem, Macro-BIM adoption: Conceptual structures, Automation in Construction. 57 (2015) 64-79. doi:10.1016/j.autcon.2015.04.018

[10] B. Succar, Building information modelling maturity matrix, Handbook of Research on Building Information Modeling and Construction Informatics: Concepts and Technologies, IGI Global. (2009) 65-103. https://doi.org/10.4018/978-1-60566-928-1.ch004

[11] T. Almuntaser, M.O. Sanni-Anibire, M.A. Hassanain, Adoption and implementation of BIM-case study of a Saudi Arabian AEC firm, International Journal of Managing Projects in Business. 11 (2018) 608-624.

[12] E. Poirier, S. Staub-French, D. Forgues, Embedded contexts of innovation: BIM adoption and implementation for a specialty contracting SME, Construction Innovation. 15 (2015) 42-65.

[13] F. Khosrowshahi, Y. Arayici, Roadmap for implementation of BIM in the UK construction industry, Engineering, Construction and Architectural Management. 19 (2012) 610-635. https://doi.org/10.1108/09699981211277531

[14] Y. Arayici, P. Coates, L. Koskela, M. Kagioglou, C. Usher, K. O'reilly, Technology adoption in the BIM implementation for lean architectural practice, Automation in Construction. 20 (2011) 189-195. https://doi.org/10.1016/j.autcon.2010.09.016

[15] A. Ghaffarianhoseini, D.T. Doan, T. Zhang, A. Ghaffarianhoseini, N. Naismith, J. Tookey, A BIM Readiness \& Implementation Strategy for SME Construction Companies in the UK, in: Proc. of the 33rd CIB W78 Conference, 2016. https://doi.org/ 10.4018/IJ3DIM.2016070103

[16] M. Machado, J. Underwood, A.J. Fleming, Implementing BIM to streamline a design, manufacture, and fitting workflow: a case study on a fit-out SME in the UK, International Journal of 3-D Information Modeling. 5 (2016) 31-46.

[17] Y. Arayici, P. Coates, L. Koskela, M. Kagioglou, C. Usher, K. O'reilly, BIM adoption and implementation for architectural practices, Structural Survey. 29 (2011) 7-25. http://dx.doi.org/10.1108/02630801111118377

[18] A.A. Abuelmaatti, V.S. Ahmed, H.S. Baban, Collaborative technologies for small and medium-sized architecture, engineering and construction enterprises: implementation survey, Journal of Information Technology in Construction (ITcon). 19 (2014) $210-224$.

[19] E. Hochscheid, G. Halin, A model to approach BIM adoption process and possible BIM implementation failures, in: Ljubljana, Slovenia, 2018.

[20] A. Ahmed, P. Kawalek, M. Kassem, A Conceptual Model for Investigating BIM Adoption by Organisations, in: Proceedings of the Joint Conference on Computing in Construction (JC3), Heraklion, Greece, 2017: pp. 447-455. doi:10.24928/JC3-2017/0103.

[21] A.L. Ahmed, M. Kassem, A unified BIM adoption taxonomy: Conceptual development, empirical validation and application, Automation in Construction. 96 (2018) 103-127. http://dx.doi.org/10.1016/j.autcon.2018.08.017

[22] G. Johnson, Managing strategic change — strategy, culture and action, Long Range Planning. 25 (1992) 28-36. https://doi.org/10.1016/00246301(92)90307-N

[23] M. Kassem, B. Succar, N. Dawood, Building information modeling: analyzing noteworthy publications of eight countries using a knowledge content taxonomy, in: American Society of Civil Engineers, 2015. http://tees.openrepository.com/tees/handle/10149/593102 (accessed August 24, 2017).

[24] H. Mintzberg, J.A. Waters, Of strategies, deliberate and emergent, Strategic Management Journal. 6 (1985) $257-272$. https://doi.org/10.1002/smj.4250060306

[25] M. Bonanomi, G. Paganin, C. Talamo, BIM implementation in Design firms. Risk-response strategies to support change management., in: 2016: pp. 1-9.

[26] N.M. Tichy, Managing Strategic Change: Technical, Political, and Cultural Dynamics, John Wiley \& Sons, 1983. https://doi.org/10.1002/hrm.3930220313

[27] G. Battisti, P. Stoneman, The intra-firm diffusion of new process technologies, International Journal of Industrial Organization. 23 (2005) 122. https://doi.org/10.1016/j.ijindorg.2004.12.002

[28] D.H. Kim, The link between individual and organizational learning, The Strategic Management of Intellectual Capital. 41 (1998) 62. https://doi.org/ 10.1016/B978-0-7506-9850-4.50006-3

[29] A. Joseph Garcia, S. Mollaoglu, M. Syal, Implementation of BIM in Small Home-Building Businesses, Practice Periodical on Structural Design and Construction. 23 (2018) 04018007. https://doi.org/10.1061/(asce)sc.1943-5576.0000362

[30] P.W. Yetton, K.D. Johnston, J.F. Craig, Computer-aided architects: a case study of IT and strategic change, Sloan Management Review. 35 (1994) $57-68$.

[31] M.L. Tushman, E. Romanelli, Organizational evolution: A metamorphosis model of convergence and reorientation., Research in Organizational Behavior. (1985).

[32] D. Miller, Evolution and revolution: A quantum view of structural change in organizations, Journal of Management Studies. 19 (1982) $131-$ 151. https://doi.org/10.1111/j.1467-6486.1982.tb00064.x

[33] D.K. Smith, M. Tardif, Building information modeling: a strategic implementation guide for architects, engineers, constructors, and real estate asset managers, John Wiley \& Sons, 2009.

[34] E. Epstein, Implementing successful building information modeling, Artech House, 2012.

[35] R.M. Panaitescu, Building Information Modeling: Towards a structured implementation process in an engineering organization, (2014).

[36] K.M. Kensek, Building information modeling, Routledge, 2014. 
Elodie Hochscheid and Gilles Halin / Proceedings of the Creative Construction Conference (2019) 119 https://doi.org/10.3311/CCC2019-119

[37] T. Kouider, J.J.G. Paterson, Architectural technology and the BIM acronym: 2; reviewing evolving paradigms for BIM implementation among SMEs., in: Architectural Technology, Towards Innovative Professional Practice: Conference Proceedings of the 5th International Congress of Architectural Technology, Aberdeen 2014 (ICAT2014), Robert Gordon University, 2014.

[38] B. Hardin, D. McCool, BIM and construction management: proven tools, methods, and workflows, John Wiley \& Sons, 2015. 